\title{
A CONSIDERATION OF THE SUBJECT OF TRAINING SCHOOLS, WITH A RECORD OF THE DEVELOPMENT OF THE TRAINING SCHOOL IN THIS HOSPITAL.
}

BY H. A. TOMLINSON, M. D., Superintendent St. Peter State Hospital, St. Peter, Minn.

During the past two years there have appeared in the medical journals, from time to time, oriticisms of the trained nurse in hospitals for the insane. One of the most interesting of these criticisms appeared in the July number of the Journal of Mental Science, and especially so because it shows what a wide difference there is in methods and detail between the institutions in this country and in England. This subject has also been under discussion in the American Medico-Psychological Association during the past three years, and the committee having the subject in charge has been continued for another year.

As the subject is still open I hope I may be pardoned for expressing some views concerning training schools, which are the result of observation and some considerable experience.

I have been very much interested in these discussions, because they illustrate so well the transition process from the asylum to the hospital, and the difficulties connected therewith, as well as the inherent drawbacks to advancement in this direction, resulting from established custom and the inertia of institutional regime. The fact that the population of our public hospitals is largely made up of chronic cases, and that, until recently, no definite separation between the acute and chronic cases has been made, is, I believe, the main hindrance to the universal adoption of the systematically organized training school, as it exists in the general hospital.

The first question to consider is, what is a trained nurse? I would answer that a trained nurse is an individual whose intelligence has been so instructed, and whose faculties have been so cultivated, that he knows what is necessary to be done for the patient placed under his care, how to do it with the least friction and most advantage, and why he does as he does. It follows as a corollary to this that his training must be of such a nature, and so carried out, that it will be applicable to the kind of patient he has to care for.

There can be no question that trained intelligence is the most efficient, and that work systematically done is more satisfactory and 
better done than that which is accomplished by haphazard means. It is also a truism that where there is a large body of people engaged in such exacting work as that involved in the care of the insane, there must be strict discipline and a rigid definition of the work. The main difficulty, so far as I can judge from the opinions expressed, lies in the widely differing conceptions of what should constitute the proper training for a nurse who is to care for the insane.

Again, a great many institution officers can not get the picture of the attendant out of their minds when considering the nurse, and others have been disappointed because they have tried to transplant the general hospital nurse into the special hospital work. The attendant had his vogue and function when our institutions were asylums, in fact, for the detention and care of the insane committed to them. This function ceased, however, as soon as the effort began to be made to change the asylum for detention into the hospital for the treatment of the insane. I regret to say that, so far as I can judge from the opinions offered, the housekeeping of the ward, and the domestic relation between the patient and employe, seem still to be of more importance than the systematic care and study of the patient from a medical standpoint; and the ability to play the cornet, sing tenor in the choir, get up card parties, and ornament the pantry shelves with colured paper seem to be more desirable than a knowledge of the habits of the patient, attention to his secretions, diet, the amount of sleep he gets, and the presence or absence of signs of suffering and disease. In other words the tendency still persists to look at the care of all patients from the standpoint of the chronic dement. Therefore, in my judgment, the difficulties which have arisen and still persist are due to the retention of the asylum regime and the effort to make it applicable to the performance of hospital work. Established customs yield slowly, and the isolation of our hospitals from public criticism, coupled with the peculiar character of their work, makes it hard to introduce new methods, especially when to do so involves increased mental effort and greater responsibility on the part of those engaged in the work.

In beginning the organization of the training school in this hospital-four years ago, we started with three assumptions based on experience and observation:

First. That the nursing work would be better done if it was entirely divorced from the ward housekeeping, our experience being 
that where the direction of these two portions of the work was combined, the medical or nursing part being the more exacting, was, when the two came in conflict, the one to be neglected.

Second. That mechanical means of restraint and isolation were like stimulants, the need for them growing with their use. Also, that in applying them, the convenience of the employe was more apt to be considered than the welfare of the patient.

Third. That in order that the recent cases might have the individual care and nursing required, and the others who were ill the proper consideration, they must be separated from the chronic healthy patients, and placed in a position to receive the detailed care and supervision necessary to their individual treatment.

All of these assumptions have been verified by experience, and, as a result, there has been evolved the present system of training, which I will now describe, prefacing it with a quotation from a report to the board of trustees of this hospital, at the time of the organization of the training school:

"It is obviously essential that any system applied to the management of a large number of people, living under the peculiar conditions surrounding an institution for the insane, where the duties are exacting and irksome, and the defenselessness of the patients makes the temptation to shirk them so strong, the duties of the employes should be thoroughly defined, and the discipline rigid. Therefore, I believe that all privileges, social or otherwise, of the medical staff and nurses should be separated as far as possible from any relation to their duty toward the patients, and the welfare of the patients should always be the primary consideration. To this end it is important that all should understand that their whole time belongs to the institution, and that privileges granted them are not absolute, but depend upon the necessities of the work of the house, and as the nurses will naturally look to those in authority over them for an example, it is important that the discipline of the staff should be as rigid as that of the nurses."

Each pupil nurse begins her course of study by serving a period of three months in caring for the chronic demented patients, with the object of learning to think and act for those who are past thinking and acting themselves. She is then transferred to a ward containing violently disturbed patients, where she learns to control herself and to not be disturbed by noise and motion. We try to teach her here how to let disturbed patients alone (the hardest thing for a nurse to learn), the wisdom of not touching them, unless 
necessary to prevent them from harming themselves or others, and the proper methods to pursue when it becomes necessary to control a violently disturbed patient. The pupil nurse is then transferred to a ward containing noisy and filthy patients, where she is taught to practice the virtues of patience, perseverance, and strict cleanliness, after which each pupil nurse serves three months on night duty. This ends the junior year of service, and the transforring from ward to ward, aside from the opportunity afforded for becoming familiar with all phases of the work, has a disciplinary value which is obvious.

During the senior year the pupil nurse spends the entire time on the reception flat. First in the operating room, where all the details of asepsis and antisepsis are learned, the giving of douches, the preparation of dressings, and the preparation of the room and patient for operation. An examination in all these requirements is given at the end of this service.

The next service is in the sick room, where all the details of sick nursing are learned, with instruction in such technical work as is required of a good nurse. The nurse then goes to the diet kitchen, and by practical work acquires the art of cooking for the sick, preparing the food, under prescription, for the patients in the sick room. At the end of this service a practical examination is also given, the nurse being required to prepare a prescribed meal. From this service the nurse passes to the bath room, where the details of hydrotherapy are taught, with massage and passive movements. Finally, the nurse spends the balance of the senior year in service on the reception ward.

We claim for this course of instruction that it is eminently practical and thorough; that there is nothing ornamental about it; that our graduates are familiar with all the details of the care of the insane; that they are taught obedience, promptness, and discretion, and that their dual training makes them better nurses for general work than those trained in a general hospital. That this training means hard work for the staff during the school year I admit, but this is more than compensated for by the reliability and increased efficiency of the service rendered by our nurses. Looking back over the past four years, during which the present system has been developing, I can see that our training school has not only trained the nurses, but has also educated public opinion to the appreciation that the insane are sick people, who come to the institution for treatment, and not merely for detention as quasi prisoners to be 
restrained of their liberty because of misdeeds resulting from insanity. The presence of the truined nurse has also eliminated from the patient's mind the horror and sense of wrong which made her so suspicious and madly resistant, thus doing away with the necessity for mechanical restraint, not on account of sentimental reasons, but because it has not been needed. Therefore our reception ward is conducted like a ward of a general hospital.

At the end of our four years' experience we are prepared to submit a fourth assumption as follows:

That it is better for the discipline of the hospital and the welfare of the patients that all nurses should leave the institution as soon as they graduate, excepting only those who have shown marked interest in and aptitude for their work, or unusual executive ability.

Any form of work that is progressive is much benefited by the infusion of new blood, and, omitting the exceptional cases, nurses do not improve after graduation, and, because opportunity for promotion is infrequent, they are apt to become restless, dissatisfied, and indifferent.

The following is the report of the year's work in the training school of this hospital, made by Dr. Chilgren, the assistant superintendent, at the graduating exercises in June, 1896:

"This evening closes the seventh year of instruction in the St. Peter State Hospital Training School for Nurses, and during that time the school has advanced to a position of marked importance and usefulness from a small beginning, when some instruction was offered to the men and women nurses separately.

"Of course, the primary object of any work that we undertake here is the good of the hospital, and therefore we train nurses in order that our patients may receive better and more intelligent attention. But that is not all. We aim to train our nurses so that they can properly care for any case of illness, and our experience has shown us that we are successful in our efforts.

"It is only during the past two years that the nurses of this hospital have done any private nursing, but the call for nurses to do outside work has been increasing steadily during that time, and in the past school year eighteen patients in different parts of the State have been nursed by graduates of this training school. The private nursing has thus far been about equally divided between the men and the women nurses.

"The course of instruction that all entering this training school 
are required to take, is made up of twenty-four months of practical work on the wards, and two graded courses of lectures and demonstrations. The ward work is so arranged that each pupil nurse has a regular term of service on all the representative wards of the hospital, coming to the wards for the reception of new patients and to the infirmary ward only after having been prepared for these positions by the instruction given in the training school and by the experience acquired during the service on the other wards. This method makes the nurses familiar with the care of all classes of patients, and gradually prepares them for the positions requiring more knowledge and judgment.

"In the training school instruction is imparted by means of lectures, study of text-books, and demonstrations. The lectures are delivered by the superintendent and the members of the medical staff. The demonstrations are given by the medical officers and by nurses who have been given special training for that purpose, and who have evinced particular aptitude for some line of work.

"During the junior year the nurses study the general principles of nursing and care of the insane, anatomy and physiology, hygiene, hospital emergencies, bandaging and surgical dressings, and the principles of surgical cleanliness.

"At the conipletion of the year's work an examination, in part written, in part practical, is held, and the nurse is required to obtain a minimum standing of 70 per cent in each branch and a general average of 75 per cent before being admitted to the second course of instruction. Pupils entering the training school before the first of December are permitted to enter the junior class of that year.

"During their senior year the nurses attend lectures in general and special sick nursing, insanity and nervous disease, dietetics, medical and surgical emergencies, and massage, and in addition are given practical instruction in surgical nursing, massage, the administration of medical baths, and in the preparation and serving of food.

"During the last year several changes have been made in our classification of the patients, and now the wards on the lower flat, in both the men's and women's departments, are devoted exclusively to recent patients and to those suffering from acute disease. This enables us to conduct these two flats purely as hospital wards, and to eliminate from them entirely the asylum idea - that is, the idea that the institution is only a place for the detention of those people 
who are unable to live and work in harmony among their kind in the social organization. Our work here is so arranged that everything that can be is done to make the patients feel that they have been sent here for treatment, and that they will be sent home as soon as they have recovered sufficiently. It is on this flat that the pupil nurse spends her second year and receives the practical part of her training. In the sick room, where all patients are put to bed on admission, and where those suffering from acute physical disease are cared for, each member of the graduating class is given, under the direction of the head sick nurse, a six weeks' course of instruction, and is taught the care of the sick in all its details. She learns to take the pulse, respiration, and temperature, how to feed the sick, and how to administer all the remedial agencies prescribed by the physicians. She learns how to observe and record the conditions of the patients and to note the changes that may occur from time to time. In this way each nurse has an opportunity to put to practical use the instruction given in the course of lectures.

"The ward diet kitchen that was established about a year and a half ago has proven an unqualified success, both from the standpoint of the patients and the training school. It adjoins the sick room and is under the immediate charge of the head sick nurse, who makes out the dietary from day to day, such changes being made by the physicians as may be needed in each particular case, and she also supervises and assists with the preparation of the food, and is responsible for the manner in which it is served.

"In this ward kitchen is prepared all food for the patients kept in bed, and for those who are up and about, but are feeble and have a poor appetite. During the past year an average of sixteen patients have been served daily from this kitchen. Each member of the senior class on the women's side has here taken a three weeks' course in preparing food for the sick. The lectures on dietetics were attended by both the men and women, but the men have received no practical instruction in this subject.

"In both the men's and women's side of the hospital we have an operating room which is devoted to surgical work, and to treatments by electricity and mechanical massage. The one on the men's side has been fitted up during the past year. Each nurse in turn is assigned to service there, and learns, first of all, cleanliness, and nothing is of more importance than cleanliness in caring for the sick. She also learns how to prepare and apply surgical dress- 
ings, and how to prepare for any surgical operation. Each member of this year's class has assisted at one or more major surgical operations and at a large number of minor cases.

"Systematic instruction in the method of giving the various kinds of medical baths was begun last year, but only a few of the members of the last year's graduating class were taught this branch, owing to the want of facilities for giving baths. This year we have had the advantage of a new and modern bath room on each of the hospital flats, and each member of this year's class has had three weeks of practical work in giving medical baths.

"This year, too, the instruction in giving massage and Swedish movements has been a part of the regular course and not limited to a few of the nurses, as was done last year. The superintendent delivers a course of lectures on the principles and practice of massage, and the practical work is done under the direction of the graduate nurse in charge of the bath room.

"In order to give you an idea of the real amount of work done, I will state that the graduate nurse in charge of the bath room, and her pupil, give massage to from four to eight patients and administer about twenty-five medical baths daily.

"As a part of their duty on the hospital flat, the nurses are taught to observe and record accurately the condition of the patients from day to day. For this history writing, as we call it, a definite programme is made out at the beginning of each week, and each nurse is assigned a certain number of patients to observe, and usually has one history to write daily. These records are examined by the physicians on the morning rounds and such changes or additions made as may be deemed necessary.

"This system teaches the nurses to observe their patients carefully and to tell what they do see, and also to tell it in better and better English.

"The present graduating class is the sixth class to complete the course of training in this school and the second class to complete the two years' graded course, and no one, after hearing the description of the cuurse, can think that the members of this class have drifted into their present positions. They have been deemed worthy of this public testimonial because they have done their work faithfully and have completed in a satisfactory manner the entire prescribed course. Theirs is not an easy or light work. Very few other vocations call for such faithfulness as nursing the insane does, if it be done properly. Nursing is an honorable and dignified call- 
ing, a profession, and one which year after year attracts young men and women of higher education and greater ability.

"Some of its exponents may not wholly honor their calling, but we honor and respect those who perform their duties faithfully, not alone for the work they do, but for the manner in which they do it, and we desire that the outside world shall honor and respect them also."

The following is a list of the questions asked on those subjects in which there was a written examination:

\section{JUNIOR EXAMINATIONS.}

BANDAGING AND SURGICAL DREBSINGS.

I. Name the materials used for making bandages, and tell the advantages of each.

II. Describe fully the method of applying a plaster of paris dressing.

III. (a) How should a wooden splint be prepared for use?

(b) For what purpose is adhesive plaster used?

IV. What is meant by asepsis and antisepsis?

V. (a) Name the most common methods of sterilization.

(b) Describe the method of dressing a clean incised wound.

VI. Describe the method of sterilizing the hands for surgical work.

VII. Describe the nethod for cleansing the skin at the site of operation.

VIII, IX, X. Practical examination in the application of various bandages. ANATOMY AND PHYBIOLOGY.

I. What change takes place in the air during respiration? (b) In the blood?

II. What is the brain?

III. Give the course of the blood through the heart.

IV. Of what does the blond consist?

V. What are the functions of the skin?

VI. Describe the different kinds of muscles.

VII. What organs are contained in the chest cavity?

VIII. What organs are contained in the abdominal cavity?

IX. What foods are acted on by the gastric juice? By the pancreatic juice?

$\mathrm{X}$. What are the functions of the bones?

I. Give rules for bathing.

II. What constitutes the impurities of the air, and what is their source?

III. Give some rules for ventilating an ordinary dwelling.

IV. What is an infectious disease? Give three examples.

HOBPITAL EMERGENCIES.

I. What should be done for a person who has fainted?

II. What would you do for the relief of a patient who was choking on a piece of food, as meat?

III. Describe a method of artificial respiration. 
GENERAL PRINCIPLES OF NUREING AND CARE OF THE INBANE.

I. Give your own idea of what qualifications are requisite to fit a nurse to care for the insane.

II. From your own experience do you believe that furce and physical restraint are better than tact, firmness, and persistence in the management of the insane, and give your reasons for preferring either method?

III. How can the subordination of an obstinate patient be attained without physical force being applied to the person of the patient?

IV. Why is it better for both nurse and patient that there should be no scuffling or use of physical force?

IV. Under what circumstances may the use of physical force be necessary, and how would you judge as to the necessity for its use?

VI. When necessary to deal with a disturbed or dangerous patient alone, what position should you assume, and why?

VII. What is the risk attendant upon the taking of food by a paralytic patient, and how is this risk to be avoided?

VIII. What two bodily functions require must attention in demented patients, and why?

IX. Why do insane patients who are physically ill require different care to that given to sane people, and in what does this difference consist?

$\mathrm{X}$. What tendency is probably present in all insane patients, and which should be constantly looked for and guarded against?

\section{SENIOR EXAMINATIONS.}

INSANITY AND NERVOUS DISEABE.

I. Why does an insane person become excited and violent when opposed?

II. What is the usual cause of an outbreak of excitement in a patient who is ordinarily quiet and sullen?

III. Why do insane people sometimes try to hide themselves?

IV. What is the difference between the motives actuating those patients who hide away and those who merely keep by themselves and resent any familiarity on the part of other patients and the nurses?

V. How would you recognize the suicidal tendency in the conduct of the patient?

GENERAL BICK NURSING.

I. Name (a) qual cations of a good nurse; $(b)$ duties to patient.

II. How would you furnish a sick room? Describe method of chang ng patient's clothing and bedding without lifting patient.

III. In what class of patients are bed sores most liable to occur? How are bed sores prevented, and how treated?

IV. Btate in detail how you would give a tub bath for the reduction of temperature. In what other ways may water be used for the reduction of temperature?

V. Name the symptoms to be observed by the nurse in every case of illness. 
VI. What is the pulse? Its normal rate and character? Its abnormalities? What is normal temperature? Its daily variations? Describe method of taking the temperature of a patient.

VII. Describe the nursing of a case of pneumonia.

VIII. Describe the nursing of a case of typhoid fever.

IX. What is an infectious disease? Give six examples.

$X$. In what different ways may medicine be administered? Describe each.

SPECLAL SICK NURSING - MEN.

I. (a) Name the different kinds of catheters.

(b) How would you care for a catheter?

II. Describe the operation of passing the catheter.

III. How would you recognize a distended bladder?

IV. (a) What is a stricture of the urethra?

(b) What may cause it?

V. What is the commonest cause of retention of urine among the insane?

SPECIAL NURSING - WOMEN.

I. Name the positions usually adopted for gynæcological treatment, and describe each.

II. What attention should a nurse give a patient the first few hours after a minor gynæcological operation, where an anæsthetic has been used?

III. What particulars would you observe in reporting upon the menstrual period of a patient? Give the normal standard in each particular.

IV. Describe the preparation of a bed for confinement.

V. How is a patient prepared for labor?

VI. What are the duties of a nurse during labor?

VII. What are the symptoms of post-partum hemorrhage?

VIII. How would you care for a patient having such a hemorrhage?

IX. Name and describe the methods of resuscitating an infant.

$X$. Name the probable signs of pregnancy.

\section{EMERGENCIRS.}

I. (a) Give the different varieties of hemorrhage.

(b) Treatment of each variety.

II. How would you move an injured person from one place to another?

III. (a) What are the signs of shock?

(b) The treatment?

IV. What would you do for a case of sunstroke?

V. How would you treat a case of poisoning when you are not certain what poison the patient has taken?

MASSAGE.

I. How many different forms of manipulation are there practiced in massage, and what do you call them?

I1. What is accomplished by these manipulations?

III. Under what conditions are the different manipulations called for?

IV. What are passive movements?

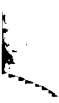


V. What do you accomplish by passive movements of a patient's body and limbs?

DIETETICS.

I. Into what two general classes are food substances divided?

II. What is the difference between them in their effect on nutrition?

III. What is the result sought in cooking starchy food?

IV. What is the result sought in cooking animal food?

V. How are these results attained?

While we do not make the claim that we have provided an ideal course of training, or that our graduates could not be improved, we have the satisfaction of knowing that the work is better and more intelligently done, and that the increased efficiency of our nursing staff more than compensates for the labor involved in their training, while those among the graduates who have done general nursing bring back with them a reputation for faithfulness, discretion, and strict obedience to the instructions of the attending physician. 